$$
\begin{gathered}
\text { 지하정보 변화객체 탐지 및 추출 연구 } \\
\text { 김광수*, 이형섭*, 김주완*† }
\end{gathered}
$$

\title{
A Study on Updated Object Detection and Extraction of Underground Information
}

\author{
Kwangsoo Kim*, Heyung-Sub Lee*, Juwan Kim*†
}

요 약

지하공간통합지도는 지하안전관리를 위해 구축되고 있으며, 주기적으로 갱신되고 있다. 통합지도 갱신은 기존에 저장된 모든 객체를 삭제하고 새로 입력된 객체들을 저장하는 절차로 진행된다. 그러나, 이 과정에 변 경되지 않은 객체들도 저장, 삭제, 저장이 반복되면서 갱신 시간을 지연하는 문제가 발생한다. 본 연구에서는 통합지도 갱신 시간을 단축하기 위해 갱신된 객체와 갱신되지 않은 객체를 분리하여, 갱신된 객체만 지하공 간통합지도에 반영하는 기술과 이 기술을 구현한 시스템을 설명한다. 갱신된 객체는 객체의 중심점을 이용한 객체 비교 방법을 사용하였으며, 검색 속도를 향상시키기 위해 쿼드트리를 사용하였다. 갱신된 객체의 유형은 객체의 형상을 이용한 추가와 삭제, 속성을 이용한 변경으로 구분하였다. 제안된 시스템은 갱신 객체 탐지, 추출, 변환, 저장 및 이력 관리 모듈로 구성되어 있다. 이 시스템은 실험에 사용한 데이터를 기준으로 기존 방법보다 약 4 배 정도 빠르게 통합지도를 갱신할 수 있는 장점이 있으며, 지상시설물과 지하시설물에 모두 적용할 수 있는 장점도 있다.

\begin{abstract}
An underground integrated map is being built for underground safety management and is being updated periodically. The map update proceeds with the procedure of deleting all previously stored objects and saving newly entered objects. However, even unchanged objects are repeatedly stored, deleted, and stored. That causes the delay of the update time. In this study, in order to shorten the update time of the integrated map, an updated object and an unupdated object are separated, and only updated objects are reflected in the underground integrated map, and a system implementing this technology is described. For the updated object, an object comparison method using the center point of the object is used, and a quad tree is used to improve the search speed. The types of updated objects are classified into addition and deletion using the shape of the object, and change using its attributes. The proposed system consists of update object detection, extraction, conversion, storage, and history management modules. This system has the advantage of being able to update the integrated map about four times faster than the existing method based on the data used in the experiment, and has the advantage that it can be applied to both ground and underground facilities.
\end{abstract}

한글키워드 : 지하정보, 통합지도, 변화객체, 객체탐지, 지도갱신

keywords : underground information, integrated map, updated object, object detection, map update

* 한국전자통신연구원 도시·공간ICT연구실

† 교신저자: 김주완(email: juwan@etri.re.kr)
접수일자: 2020.11.19. 심사완료: 2020.11.20.

게재확정: 2020.12.21. 


\section{1. 서 론}

도심지 지하에 설치된 시설물들은 눈으로 상 태를 직접 확인할 수 없으므로 손상 정도를 파악 하는 것이 매우 어렵다. 따라서, 지하시설물의 손 상으로 도심지에서 지반침하라는 사회 문제가 계 속 발생하고 있으며, 인적 및 물적 손실이 증가 하고 있다. 전국에서 발생한 지반침하 사고는 2015년 191건에서 2018년 342건으로 3년 동안 두 배 정도 증가하였고, 2019년에는 192건이 발생하 였다[1, 2]. 2019년에 지반침하 발생 건수가 이전 연도보다 감소한 것은 지반침하 발생을 예방하기 위한 범부처의 다양한 노력의 결과이다. 그림 1 은 연도별 지반침하 발생 현황을 표시하고 있다. 지반침하를 발생시키는 원인은 다양하지만 낡은 하수관의 손상이 주요 원인으로 지목되고 있다. 표 1은 2019년 발생한 지반침하 발생 현황을 원 인별로 분류하여 표시하고 있다.

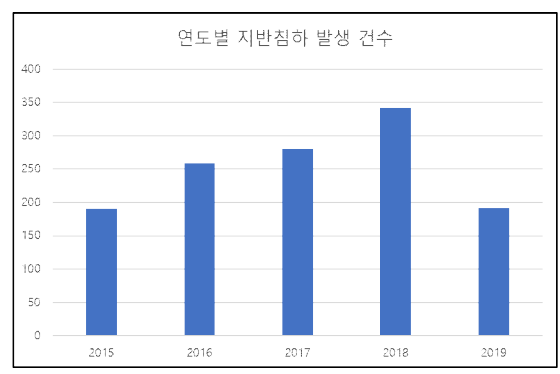

그림 1. 지반침하 발생 현황

Fig. 1. Status of ground subsidence

지반침하 사고는 선제적인 예방 활동이 중요 하므로 국토교통부에서는 지하에 매설된 시설물 과 구조물인 상수관로, 하수관로, 가스관, 전력선, 통신구, 지하철 역사 등 사회 기반 시설의 체계 적 관리와 현황 파악을 위해 지하공간 통합지도 를 3차원 기반으로 2015년부터 제작하고 있다[3, 4]. 이 사업은 전국 모든 지방자치단체를 대상으 로 3차원 지하공간 지도를 제작하는 것을 목표로
하고 있으며 2023년에 종료될 예정이다. 지하공 간 통합지도는 지방자치단체 및 유관기관이 보유 하고 있는 15 종의 지하정보를 대상으로 한다. 지 하정보는 지하시설물 6종 (상수, 하수, 난방, 전 기, 가스, 통신), 지하구조물 6종 (지하철, 지하 보도, 지하차도, 지하주차장, 지하상가, 공동구) 및 지반 정보 3 종 (시추, 관정, 지질 정보)을 포 함한다[3-5].

표 1. 원인별 지반침하 발생 현황 [2] Table 1. Status of ground subsidence by causes

\begin{tabular}{|c|c|}
\hline 발생 원인 & 2019 \\
\hline 상수관 손상 & $8(4.2 \%)$ \\
\hline 하수관 손상 & $98(51.0 \%)$ \\
\hline 기타매설물 손상 & $4(2.1 \%)$ \\
\hline 굴착공사 부실 & $6(3.1 \%)$ \\
\hline 다짐 불량 & $19(9.9 \%)$ \\
\hline 상·하수관 공사 부실 & $3(1.6 \%)$ \\
\hline 기타 매설공사 부실 & $9(4.7 \%)$ \\
\hline 기타 & $45(23.4 \%)$ \\
\hline 합계 & $192(100 \%)$ \\
\hline
\end{tabular}

지하공간 통합지도는 지방자치단체 및 유관기 관들이 각자 관리하는 지하공간 지도를 통합지도 관리기관에 $\mathrm{shp}$ 형태의 파일로 제공한다. 지하공 간 통합지도 관리기관에서는 데이터베이스에 저 장된 기존 객체를 모두 삭제하고 신규로 받은 파 일에 포함된 모든 객체를 갱신 여부와는 상관없 이 모두 데이터베이스에 저장한다. 이러한 방법 을 통판 지도 갱신이라고 하며 지하공간 통합지 도 관리기관에서는 저장한 2 차원 지하정보를 3 차 원 정보로 변환한다. 통판 지도 갱신 방법은 갱 신 과정이 단순한 장점이 있으나, 갱신되지 않은 객체를 삭제하고 다시 저장하고 이미 만들어진 3 차원 객체를 삭제하고 다시 변환함으로써 지도 갱신 과정에 많은 시간을 사용하는 단점이 존재 
한다. 특히, 3 차원 변환과정은 2 차원 지도 갱신보 다 더 많은 시간이 소요된다.

따라서, 본 논문에서는 기존에 저장된 지도와 신규로 입력된 지도를 비교하여 갱신된 객체와 갱신되지 않은 객체를 구분하고, 갱신된 객체만 을 지하공간 통합지도 데이터베이스에 저장함으 로써 지도 갱신 시간을 단축하는 기술과 시스템 을 제안하였다. 제안된 시스템은 갱신 객체 탐지 모듈, 갱신 객체 추출 모듈, 갱신 객체 변환 모듈, 갱신 객체 저장 모듈 및 갱신 객체 이력 관리 모 듈로 구성되어 있다. 탐지 모듈에서는 지하정보 객체를 대표하는 중심점을 계산하고, 선택된 중 심점을 이용하여 신규 객체와 원본 객체 사이의 갱신 여부를 탐지한다. 추출 모듈에서는 갱신 객 체를 갱신 유형에 따라 분류하고, 변환 모듈은 갱신된 객체를 표준 형식으로 변환하고, 저장 모 듈은 갱신 유형에 따라 갱신 객체를 shp 파일로 저장하고, 이력 관리 모듈은 갱신된 객체의 이력 을 관리한다. 통판 지도 갱신 방법과 제안된 방 법의 성능을 비교한 결과 제안된 방법이 통판 지 도 갱신 방법보다 4 배 정도 빠르게 선형으로 구 성된 공간지도를 처리할 수 있음을 확인하였다.

기존의 수치지도 부분갱신 기술에서는 GPS 수신 위치, 공사현황 수집자료, 항공사진 등을 이 용하여 수치지도를 부분적으로 변경한다. 그러나, 이 기술들은 실세계에서 변경된 부분만을 추출하 여 기존 지도에 반영하는 것으로 본 연구에서 해 결하고자 하는 지도와 지도를 비교하여 변경된 객체를 찾아내는 접근 방법과는 상이하다.

본 논문의 구성은 다음과 같다. 2장에서는 수 치지도 부분갱신 기술에 관한 선행 연구를 소개 하고, 3장에서는 제안하는 갱신 객체 탐지 및 추 출 시스템에 대하여 설명하고, 4장에서는 제안된 방법과 통판지도 사이의 실험 결과를 분석하고, 마지막으로 5장에서 결론과 향후 연구 계획을 제 시하고 논문을 마무리하였다.

\section{2. 관련연구}

이번 장에서는 지도의 최신성 확보를 위해 현 실 세계에서 발생한 부분적 변경을 검출하여 기 존에 제작된 전체 지도에 반영하는 부분지도 변 경 기술에 대하여 논의한다.

도로지도 부분 변경 기술은 차량용 네비게이 션에 주로 사용되고 있다. Mapscape사의 조사에 따르면 일반적으로 도로는 매년 15\% 정도 변경 이 발생한다[6]. 따라서, 도로 전체 지도를 한 번 에 변경하기보다는 변경된 부분만을 수시로 찾아 내어 차량용 도로지도를 즉시 변경하는 것이 주 행의 안전성 향상에 유리하다. 도로지도 부분 변 경 기술은 주로 차량에 설치된 GPS 수신기에 저 장된 차량의 이동 위치 좌표를 이용한다 $[7,8]$. 차량의 이동 좌표와 기존의 도로지도를 비교하여 신규로 건설된 도로를 수시로 찾아낸다. 그러나, 이 방법은 신규 도로로 추정할 수 있는 충분한 수량의 차량 이동 좌표가 있어야 하고, 차선 수 나 폭과 같은 도로의 속성 정보를 찾지 못하는 단점이 있다.

도로지도를 부분적으로 변경하는 다른 기술은 이동통신을 이용하여 차량용 네비게이션 도로를 부분적으로 변경하는 방법이다[9, 10]. 기존에는 차량에 설치된 주행 안내 시스템에 장착된 메모 리를 탈착 후 인터넷 연결이 가능한 컴퓨터에 연 결하여 지도 제작 업체가 제공하는 전체 신규 지 도를 한 번에 다운로드하여 지도를 변경하였다. 그러나, 이동통신의 발달로 차량의 이동 중에 변 경이 발생한 지역의 지도 데이터만을 차량에 수 신하여 주행 안내에 사용하는 전체 지도를 변경 하는 기능을 주요 자동차 제조사들이 선호한다. 이 방법은 현실 세계의 도로가 변경될 때 수시로 차량에 탑재된 지도를 변경함으로써 운전의 안전 성 향상에 기여한다. 그러나, 이 방법은 차량에 설치된 전체 지도와 수신한 부분 변경 지도가 함 
께 사용하는 객체 식별자가 존재하고 이 식별자 는 변경이 발생하지 않는다는 조건이 만족 될 때 만 유효하게 사용할 수 있는 제약이 있다.

수치치도 부분 갱신기술은 지형과 지상물의 변화된 상황을 GIS 수치 기본도에 신속히 반영 하기 위해 제안되었다[11]. 제안된 기술은 공사현 황 수집자료, 위성사진, 항공사진 등을 이용하여 변화지역을 조사하고, 변화지역에 대한 현황측량 및 지적 측량을 통해 변경상황을 수치지도에 반 영함으로써 지도의 최신성을 유지하고자 하였다.

상기에 논의된 도로지도와 수치지도 부분 변 경 기술들은 변경이 발생한 일부 부분을 기존에 존재하는 전체 지도에 반영하는 기술을 제시하고 있으나, 논 본문의 주제인 신규 전체 지도와 기 존 전체 지도 사이에 변경된 부분만을 찾아내는 데에 적용하기에는 두 가지 어려움이 있다. 첫 번째, 지하공간에서는 GPS를 이용한 위치 좌표 확인이 어렵다. 두 번째, 본 논문에서 논의하는 환경에서는 신규 지도와 원본 지도 사이에 변경 되지 않는 식별자가 존재하지 않으므로 기존의 방법을 적용할 수 없다. 따라서, 변경되지 않는 식별자가 존재하지 않는 환경에서 지도와 지도 사이의 변경 부분을 찾을 수 있는 새로운 방법의 개발이 필요하다.

\section{3. 지하정보 갱신객체 탐지 시스템}

\section{1 시스템 구조}

지하정보 변화객체 탐지 시스템 (Updated Object Detection for Underground Information, UODUI)의 구조는 그림 2에 표시하였다. UODUI 시스템은 갱신파일 모니터링 시스템과 3차원 변 환 시스템과 연동되어 동작한다. 세 개의 독립된 시스템은 공통으로 처리대상 파일을 특정한 폴더 에 저장하고, 폴더 정보와 폴더에 저장된 파일
정보를 Message Queue를 이용하여 상호 전달한 다. 파일은 shp 포맷으로 저장되어 있다. 갱신 파 일 모니터링 시스템은 지하정보를 보유하고 있는 기관들과 온라인/오프라인으로 연결하여 수신된 파일에 갱신된 객체가 포함되어 있는지를 확인하 고, 갱신된 객체를 포함한 파일을 UODUI에 제공 한다. UODUI는 수신한 파일에서 갱신된 객체만 을 분리하여 갱신 유형에 따라 저장하고, 저장된 갱신 객체 파일 정보를 3 차원 변환 시스템에 제 공한다. 3 차원 변환 시스템은 갱신된 2 차원 객체 를 3 차원 정보로 변환하고, 변환된 3 차원 정보와 2 차원 갱신 객체를 함께 지하공간 통합지도에 저 장한다. UODUI는 갱신 객체 탐지, 추출, 변환, 저장, 및 이력관리 모듈로 구성되어 있다.

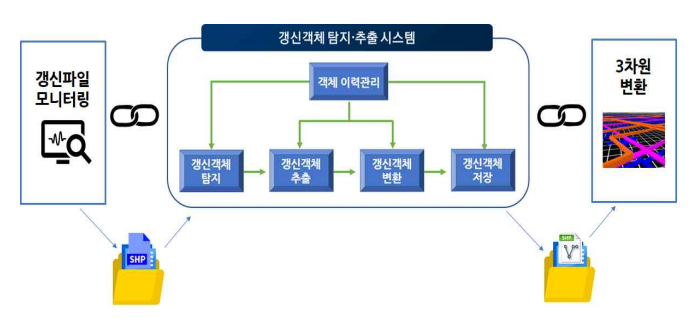

그림 2. 시스템 구조

Fig. 2. System architecture

\section{2 갱신 객체 탐지 모듈}

갱신 객체 탐지 모듈은 수신된 파일에 존재하 는 갱신된 객체를 찾아내는 기능을 수행한다. 갱 신된 객체를 찾기 위해서 수신된 파일에 포함된 객체와 기준 파일에 포함된 객체를 비교한다. 여 기에서 신규 파일은 현재 입력된 파일이고, 기준 파일은 이전에 입력된 파일로 두 가지 파일은 모 두 같은 지역을 대상으로 하며 같은 기관에서 제 공한 것이다.

신규 객체와 기준 객체를 빠르고 효율적으로 검색 및 비교하기 위해 두 가지 방법을 적용하였 다. 하나는 중심점 기반의 객체 비교 방법이며, 
다른 하나는 쿼드트리 (Quadtree)를 이용한 색인 방법이다. 중심점은 단일 지하정보 객체의 형상 을 포함하고 있는 최소 사각형인 $\mathrm{MBR}$ (Minimum Bounding Rectangle)의 중심 좌표를 의미한다. 객체의 중심점 $\mathrm{Cx}, \mathrm{y}=((\mathrm{MinX}+$ $\mathrm{MaxX}) / 2$, $(\mathrm{MinY}+\mathrm{MaxY}) / 2)$ 으로 계산하였 다. $\mathrm{MBR}$ 과 중심점은 그림 3에 표시하였다. 신규 객체와 기준 객체들의 중심점 사이의 거리를 계 산하여 계산된 거리가 일정 기준(alpha)을 초과 하면 서로 다른 객체로 판단하고, 일정 기준 이 하이면 각 객체의 속성과 실제 위치 좌표를 비교 하여 동일 객체 여부를 판정한다. 두 객체 사이 의 거리가 일정 기준 (beta) 이내일 때만 동일 객 체로 간주한다. 이때 alpha와 beta는 각각 $0.01 \mathrm{~cm}$ 와 $1 \mathrm{~cm}$ 로 설정하였다.

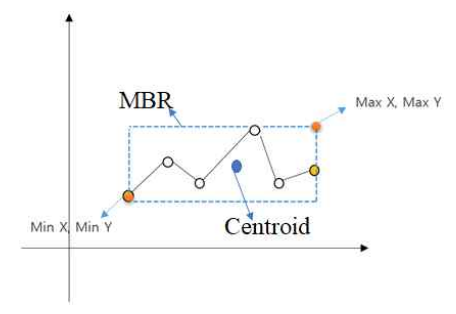

그림 3. $\mathrm{MBR}$ 과 중심점

Fig. 3. MBR and centroid

객체 검색 시간을 빠르게 하려고 사용한 쿼드 트리는 기준 파일에 포함된 모든 객체가 위치하 는 전체 2 차원 공간 영역을 4 등분하고, 각각의 사분면을 또다시 4 등분하는 작업을 반복하고, 각 각의 객체를 트리에 저장하였다. 따라서, 입력된 신규 객체는 자신의 중심점과 쿼드트리의 각 사 분면을 비교하여 자신이 속하는 사분면으로 진행 하는 작업을 자신과 동일한 객체가 검출될 때까 지 반복한다. 이런 방법으로 검색 대상이 되는 객체들의 수를 계속 $1 / 4$ 씩 줄여나감으로써 검색 시간을 단축한다.

\section{3 갱신 객체 추출 모듈}

갱신 객체 탐지 과정에서 갱신된 것으로 판정 된 객체는 별도의 메모리로 저장된다. 추출된 갱 신 객체는 갱신 유형에 따라 추가, 삭제, 변경으 로 분리된다. 추가는 기존 파일에는 없는 객체가 신규 파일에 존재하는 것을 의미하며, 삭제는 기 존 파일에 존재하는 객체가 신규 파일에는 없는 객체를 의미하며, 변경은 객체의 형상은 동일하 나 객체의 속성이 변경된 것을 의미한다. 따라서, 객체의 형상 비교를 통해 갱신 객체를 추가 및 삭제 유형으로 분류하고, 속성 비교를 통해 변경 으로 분류한다.

\section{4 갱신 객체 변환 모듈}

갱신 객체 변환 모듈은 갱신된 객체의 형상 및 속성의 형식을 표준 포맷으로 변환한다. 현재 사 용하는 표준 포맷은 국토부에서 정의한 지하공간 통합지도 표준 양식이다. 입력된 객체의 형식과 출력된 객체의 형식이 현재는 동일하므로 별도의 기능을 수행하지는 않고 있다. 향후, 본 연구를 통해 새로운 표준 포맷이 정의될 때, 입력된 데 이터의 포맷이 정의된 포맷과 다른 경우 표준 포 맷 변환 기능이 유용하게 사용될 것이다.

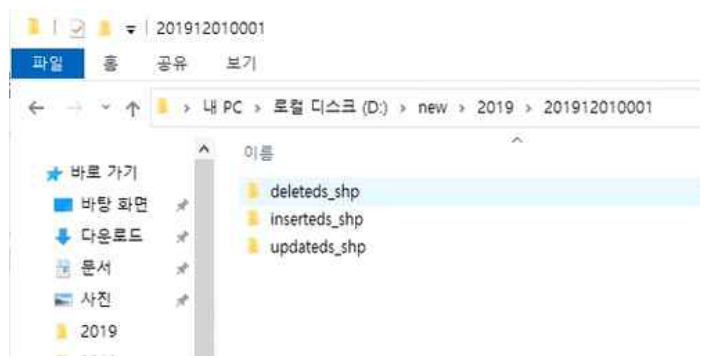

그림 4. 갱신 유형별 폴더 생성

Fig. 4. Folder creation by updated types 


\section{5 갱신 객체 저장 모듈}

갱신 객체 저장 모듈은 갱신 객체 추출 모듈에 서 갱신 유형별로 분류한 객체들을 각각의 유형 에 맞추어 파일로 저장하는 기능을 수행한다. 여 기에서 저장된 폴더 이름이 3차원 변환 시스템으 로 전달된다. 객체들이 저장될 때는 3.4절에서 정 의된 표준 포맷을 사용하고, 파일 형식은 shp를 사용한다. 추가(inserted), 삭제(deleted), 변경 (updated) 폴더를 생성하여 파일을 저장한 결과 를 그림 4에 표시하였다.

\section{6 갱신 객체 이력 관리 모듈}

갱신 객체 이력 관리 모듈은 갱신 객체 탐지 및 추출 결과에 대한 통계적인 정보를 제공한다. 날짜, 기관, 갱신 유형 등의 조건을 기반으로 갱 신된 객체의 저장된 정보를 검색하여 통계 정보 를 생성한다. 생성된 정보는 객체 갱신이 발생하 는 경향성을 파악하는데 도움을 준다. 그림 5 는 갱신 객체 이력을 검색한 결과를 표시하고 있다.

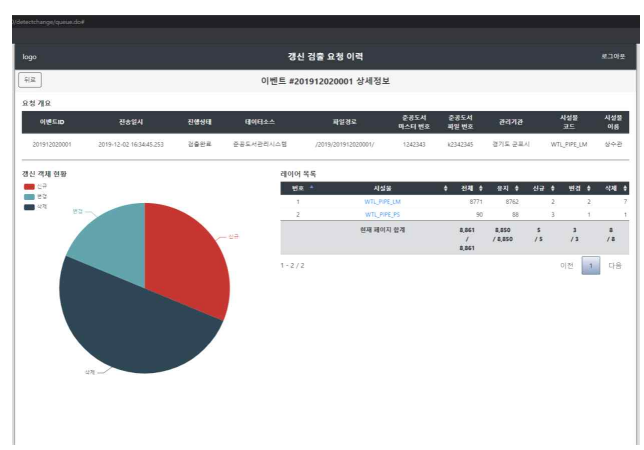

그림 5. 갱신 객체 이력 검색 화면 Fig. 5. History search for updated objects

\section{4. 실험결과}

\section{1 실험 환경}

$\mathrm{UODUI}$ 의 성능을 확인하기 위해 여러 종류의 데이터 세트를 이용하여 실험을 진행하였다. 실 험 환경은 표 2에 표시하였다. UODUI의 지도 갱 신 시간은 객체에 대한 연속 검색을 이용한 지도 갱신 및 통판 지도 갱신 시간과 비교하였다. 실 험에서 사용된 데이터의 종류는 표 3에 표시하였 다. UODUI는 지하시설물을 포함한 선형의 형상 을 가지는 모든 데이터에 적용할 수 있다. 따라 서, 실험용 데이터로 지하시설물인 하수관 뿐만 아니라 지상시설물인 철도중심선과 및 도로망을 비교 대상으로 하였다. 실험 방법은 기존 지도와 신규 지도에 포함된 객체를 비교하여 갱신 객체 를 추출하여 갱신 유형별로 갱신 객체를 분류한 후 갱신 유형별 파일을 생성하였다. 기존 지도 객체 중 약 $10 \%$ 정도의 객체를 변경하여 신규 지도를 생성하여 갱신 객체 탐지, 추출, 저장 기 능을 실험하였다.

표 2. 실험 환경

Table 2. Experiment environment

\begin{tabular}{|c|c|}
\hline CPU & Intel Core i7 Quad Core \\
\hline RAM & $16 \mathrm{~GB}$ \\
\hline SSD & $1 \mathrm{~T}$ \\
\hline 운영체제 & CentOS 2.6 .32 \\
\hline 개발언어 & Java JDK 1.8 \\
\hline
\end{tabular}

표 3. 실험용 데이터

Table 3. Experimental data

\begin{tabular}{|c|c|c|}
\hline $\begin{array}{c}\text { 데이터 } \\
\text { 이름 }\end{array}$ & $\begin{array}{c}\text { 데이터 } \\
\text { 크기 }(\mathrm{MB})\end{array}$ & $\begin{array}{c}\text { 데이터 } \\
\text { 수량 }\end{array}$ \\
\hline 철도망 & 1.48 & 1,373 \\
\hline 하수관 & 9.25 & 18,075 \\
\hline 도로망 & 144 & 246,768 \\
\hline
\end{tabular}




\section{2 지도 갱신 시간}

UODUI의 수행 시간과 통판 지도 갱신 및 연 속 검색의 지도 갱신 시간을 그림 6에 표시하였 다. 지도 갱신 시간은 지도로부터 객체를 읽기 시작하는 순간부터 별도의 파일에 갱신 객체의 저장이 완료하는 순간까지의 차이로 계산하였다. 신규 지도와 기존 지도 모두 shp 형식의 파일에 저장되어 있으며, 갱신된 객체는 Postgresql에 저 장하였다. Postgresql은 본 논문의 연구 성과를 적용하고 운영할 지하정보활용지원센터에서 사 용하는 것과 동일한 종류이다.

UODUI는 전처리 과정에서 기존 지도를 읽어 서 쿼드 트리를 생성한다. 신규 지도 파일이 입 력되면 이 파일에 있는 객체를 하나씩 메모리로 로드하고 쿼드트리에 입력하여 이 객체와 동일한 객체가 쿼드트리에 존재하는지 여부와 객체가 갱 신되었는지 여부를 판정한다. 이 과정에서 갱신 된 객체만 Postgresql에 저장한다. 통판지도 갱신 은 신규 지도에 포함된 모든 객체를 하나씩 읽어 서 Postgresql에 저장한다. 연속 검색은 신규 지 도에 포함된 객체를 하나 읽어서 기존 지도에 있 는 모든 객체와 1 대 1 로 비교하면서 객체의 갱신 여부를 판정하였다. 연속 검색에서도 갱신된 객 체만 Postgresql에 저장한다. Postgresql에 저장 된 갱신 객체 이력은 그림 7에 표시하였다.

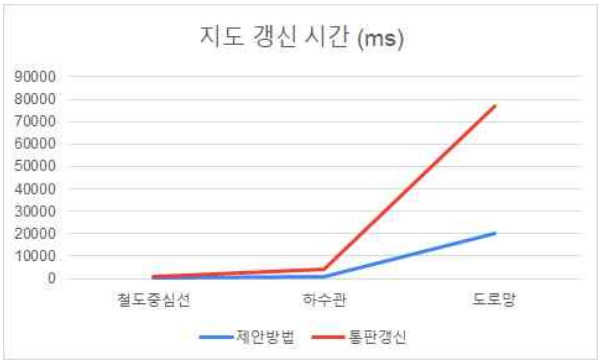

그림 6. 지도 갱신 시간 비교 Fig. 6. Comparison of map update time
실험에 사용한 세 가지 방법은 모든 갱신된 객 체를 탐지하였다. UODUI는 처음 실험에서는 탐 지율이 $100 \%$ 미만이였으나, 오류가 발생한 갱신 객체의 형상을 분석하고 필요한 변수들을 조정하 여 모든 갱신된 객체를 탐지할 수 있었다. 따라 서, 갱신 객체의 형상에 영향을 받지 않는 방법 에 관한 추가연구가 필요하다.

그림 6에서 알 수 있듯이, UODUI는 지도에 포함된 객체 수량이 많아질수록 좋은 성능을 나 타낸다. 특히, 가장 데이터 수가 많은 도로망 데 이터에 대해서는 기존의 통판지도 갱신 방법 보 다 약 4 배 정도 지도 갱신 시간을 단축하였다. 이러한 현상은 UODUI를 구성하는 색인으로 인 해 발생한다. 중심점을 기반으로 동일 객체를 판 별하는 과정에서 색인을 이용함으로써 동일 객체 여부를 판별하는 후보 객체들의 수가 대폭 감소 된다. 따라서, 검색 시간을 급격히 단축시키는 장 점이 있다.

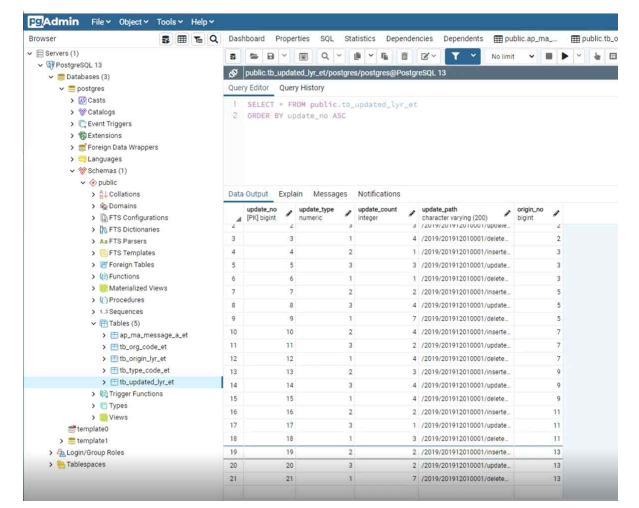

그림 7. 갱신 객체 이력 저장 결과

Fig. 7. Results of saving updated objects

\section{5. 결 론}

본 논문에서는 신규 지도와 기존 지도를 비교 하여 갱신이 발생한 객체만을 선별하여 저장함으 
로써 지도 갱신 시간을 단축하는 지하정보 변화 객체 탐지 및 추출 기술과 이 기술을 구현한 시 스템에 대해 설명하였다. 갱신이 발생한 객체는 지하정보의 형상을 비교하여 찾은 신규 및 삭제, 속성을 비교여 찾은 변경으로 분류되어 각각 별 도의 폴더에 파일로 저장하였다. 제안된 방법은 신규 지도와 기존 지도에 포함된 객체들의 식별 자를 비교 대상으로 사용할 수 없는 환경에서 갱 신 객체를 효과적으로 탐지할 수 있다. 제안된 시스템은 갱신된 객체를 탐지하기 위해 갱신 객 체 탐지, 추출, 변환, 저장 및 이력 관리 모듈로 구성하였고, 지하정보 객체의 중심점을 비교하는 방법과 쿼드트리를 이용한 인덱싱 방법을 적용하 여 갱신 객체 탐지 시간을 감소시켰다. 제안된 방법은 데이터의 수량이 증가할수록 더 좋은 성 능을 나타낸다. 또한, 제안된 방법은 선형의 형상 으로 표현되는 하수관, 상수관과 같은 지하시설 물 뿐만 아니라 동일 형상으로 표현되는 도로, 철도와 같은 지상시설물에도 적용할 수 있는 장 점이 있으며, 갱신 객체의 형상에 영향을 받는 부분을 조정한 결과 탐지율도 $100 \%$ 에 이른다.

본 논문에서 제안된 방법은 2 차원 지도 갱신 시간을 단축할 뿐만 아니라 갱신된 객체를 3 차원 객체로 변환하는 시스템에서도 입력으로 주어지 는 변환대상 객체의 수량을 감소시켜 3차원 지도 갱신 시간도 함께 단축시킴으로써 지하공간 통합 지도 실시간 갱신 체계 구축에도 중요한 역할을 담당할 것으로 예상된다.

향후, 실제 업무에서 사용되는 더 많은 종류의 지하공간 지도에 적용하여 실세계에서 발생할 수 있는 다양한 갱신 객체를 분석하고 제안된 시스 템을 구성하는 각각의 모듈의 성능을 개선할 뿐 만 아니라 안정성 및 효율성을 향상시켜 실무에 적용할 계획이다. 또한, 다양한 형태의 갱신된 객 체의 형상을 모두 탐지할 수 있도록 갱신 객체 탐지 및 추출에 관한 최적화 연구가 필요하다.
본 연구는 국토교통부/국토교통과학기술 진흥원의 지원으로 수행되었음 (과제번호 20DCRU-B158151-01).

\section{참 고 문 헌}

[1] http://www.waterjournal.co.kr/news/article View.html?idxno=46623, September 2019.

[2] http://www.sj-ccnews.com/news/articleVie w.html?idxno=7240, Feburuary 18, 2020.

[3] 전종암, 이재흠, 신철호, 최창호, 이성진, 염 병우, 이인환, "사물인터넷(IoT) 기반 도시 지하매설물 모니터링 및 관리시스템 기술", 전자통신동향분석, 제 30 권 5 호, pp. 28-38, October 1, 2015. DOI: https://doi.org/10. 22648/ETRI.2015.J.300504

[4] 박동현, 장용구, 최현상, "지하안전관리 지원 을 위한 3차원 지반 정보 구축 방안 연구”, 한국지리정보학회지 제 21권 1호, pp. 23-34, March 2018. DOI : http://dx.doi.org/10. 11108/kagis.2018.21.1.023

[5] 이석민, 윤형미, "도심지 지반함몰에 관한 예방정책 개선안 연구”, 서울도시연구, 제 18 권 1호, pp. 27-42, March 2017. URL: http://www.dbpia.co.kr/journal/articleDetail? nodeId=NODE07183493

[6] http://mapscape.eu/telematics/incrementalupdating.html (last date accessed: 2 Octorber 2020.)

[7] R. Stanojevic, S. Abbar, S. Thirumuruganathan, G. D. Francisci Morales, S. Chawla, F. Filali, and A. Aleimat, "Road network fusion for incremental map updates", Progress in Location Based Services 2018, Springer, pp. 91-109, January, 2018. DOI: https://doi. org/10.1007/978-3-319-71470-7_5

[8] M. Vesely, C. Novak, A. Reh, and H. Mayr, "Incremental Navigation Map 
Enhancement with GPS Tracks from Heterogeneous Sources", Proceedings of the International Conference on Artificial Intelligence, July 14-17, Las Vegas, Nevada, USA, vol. 2, pp. 787-793, 2008. URL: https://www.researchgate.net/publica tion/220835036_Incremental_Navagation_Ma p_Enhancement_with_GPS_Tracks_from_He terogeneous_Sources

[9] 민경욱, 안경환, 김주완, 진성일, “부분 맵 업데이트 지원 내비게이션을 위한 모바일 공간 DBMS 개발 및 성능 평가", 정보처리 학회논문지D 제5-D권 제5호 pp. 609-620, October 2008. URL:http://www.dbpia.co.kr/ journal/articleDetail?nodeId=NODE01352587

[10] https://gisuser.com/2014/02/hyundai-mnsoft -develops-new-incremental_update-technol ogy-for-navigation-system-while-driving, 2014.

[11] 신상철, 조재관, 김경휘, "GIS 기본도 부분 갱신 방안에 관한 연구”, 대한공간정보학회 학술대회, pp. 199-202, April 2009. URL: http://www.dbpia.co.kr/journal/articleDetail? nodeId=NODE01307935
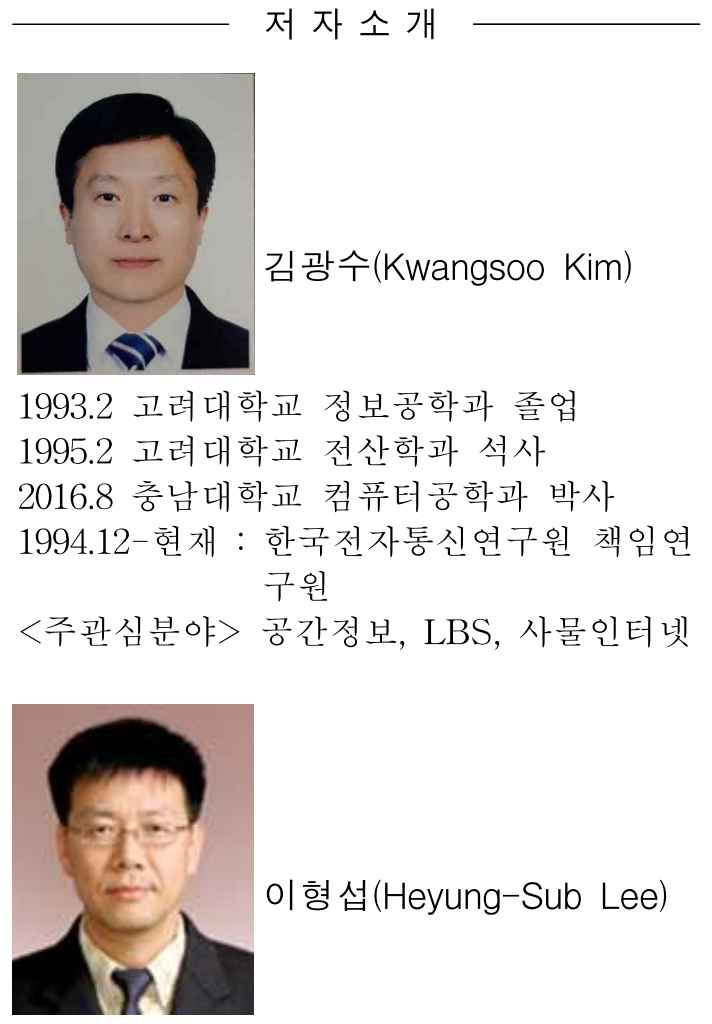

이형섭(Heyung-Sub Lee)

1986.2 충남대학교 전자공학과 졸업 1994.8 충남대학교 전자공학과 석사 2002.8 충남대학교 전자공학과 박사 1984.12-1990.8 삼성전자 주임연구원 1990.9-현재 : 한국전자통신연구원 책임연 구원

<주관심분야>IoT통신, 디지털트윈

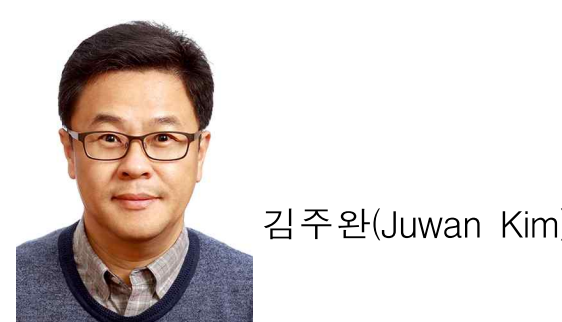

1993.2 부산대학교 컴퓨터공학과 학사 1995.2 부산대학교 컴퓨터공학사 석사 2004.2 충남대학교 컴퓨터과학과 박사

1995.1-현재 : 한국전자통신연구원 책임연 구원

<주관심분야> 공간정보, 영상처리 